\title{
FANTÁSTICO E REALIDADE COTIDIANA: VISÕES POSSÍVEIS
}

\section{Belmira Magalhães ${ }^{(*)}$}

Resumo: Este artigo parte do lugar teórico que considera a representação literária uma práxis humana que partindo do cotidiano cria uma nova realidade, voltando ao cotidiano para resignificá-lo transformando, quando isso é possível, as subjetividades que realiza e recebem o reflexo estético. Desse ponto de vista, a forma que o escritor escolheu para dizer um determinado conteúdo por mais que possa parecer distanciada da realidade social estará realizando um diálogo com ela. Heliônia Ceres no livro de contos Olho do besouro, a partir de diversas maneiras que têm em comum a busca de soluções fantásticas para as impossibilidades de ultrapassagem das barreiras sociais, discute as relações de classes, g6enero e idade, na sociedade contemporânea.

Palavras-chave: Representação social; representação literária; fantástico; reflexo estético

Este artigo representa um desafio intrigante, pois relaciona, a partir da análise de uma narrativa, a teoria da literatura ligada à noção de representação literária e o realismo fantástico. Na verdade, busca-se verificar a sintonia entre a narrativa fantástica e o que Antonio Candido chama de redução estrutural.

O processo por cujo intermédio a realidade do mundo e do ser se torna, na narrativa ficcional, componente de uma estrutura literária, permitindo que esta seja estudada em si mesma (CANDIDO, 1993, p.9).

O livro Olho de besouro, de Heliônia Ceres (1988), transita entre o cotidiano mais primitivo das relações familiares e a negação aparente das possibilidades de resolução dos conflitos desse grupo, por seres humanos comuns. Nas narrativas há uma busca do transcendente, que pode vir configurado sob a forma da Natureza - o vento que tudo comanda; ou sob o apelo religioso que liga contraditoriamente Deus e o Diabo.

(*) Doutora em Literatura e sociedade. Professora do Programa de Pósgraduação em Letras e Lingüística e do Mestrado em Ciências Sociais da Ufal. 
Parte-se do pressuposto de que toda representação literária é uma representação das relações sociais, seja qual for a forma escolhida pela autoria para desenvolver a temática. Há uma intencionalidade autoral objetivada na narrativa sob determinada forma, constituindo o momento ímpar do reflexo estético. Nessa atividade parte-se sempre do cotidiano, para ultrapassá-lo e voltar a ele com uma nova roupagem, que contém, agora, uma reflexão da subjetividade.
A eleição de um grupo contextual de objetos, sua conversão e mundo mediante a refiguração e a conformação mimética, é impossível sem uma tomada de posição com respeito àquele conteúdo e suas conexões, tomada de posição que constitui o ser-assim da parte do mundo eleita e sua elevação ao "mundo" estético (LukácsCS, v.2. 1966-7, p.241).

Para a crítica literária, a narrativa fantástica desliga-se do cotidiano, passando a obedecer a códigos diferentes.

Pode-se dizer que o real faz piruetas desconhecendo os princípios lógicos que caracterizam o cotidiano das pessoas. Está-se, pois, diante da fantasia do real ou, mais precisamente, diante do realismo fantástico (GOULART, 1995, p.26).

Para esse autor, o fantástico pretende, com essa forma de representar literariamente, derrubar definitivamente a noção de verossimilhança tão cara à escola realista. No entanto, queremos ressaltar que, mesmo nas narrativas fantásticas, há uma representação da realidade que necessariamente só pode ser compreendida pela inserção da obra no mundo e como, da mesma forma que a mais realista narrativa, não pode ser nunca um reproduzir mecânico da sociedade, mas uma específica relação entre o conteúdo, na qual há um tema a ser explorado, e uma forma escolhida pela autoria para fazê-lo. Uma obra será convincente ou, ao contrário, deixará lacunas, não por sua capacidade de refletir o real pelas maneiras mais diversas de que se tem notícia ou e pelas que serão ainda descobertas, mas pela capacidade de chegar à particularidade artística!. O que está em jogo não é a escola a que o autor pertence, pois

Para desenvolver o conceito de particularidade artística, ver Lukács (1996-67) e Magalhães (2001). 
a capacidade que os textos possuem de convencer depende mais da sua própria organização que da referência ao mundo exterior, pois este só ganha vida na obra literária se for definitivamente ordenado pela fatura (CANDIDO, 1993, p.11).

Segundo ainda esse autor, o que deve nortear qualquer crítica, tanto a que se dirige aos textos realistas, quanto aos não-realistas, é a verificação da capacidade das narrativas de suscitar no leitor uma impressão de verdade porque conseguiram uma articulação interna coerente.

Nesse sentido, a afirmação de Goulart(1995) sobre a distância entre a ficção realista e os componentes extraliterários no fantástico fica prejudicada, pois estes sempre ocorrerão.

A consequiência imediata é a ruptura da ligação da obra literária com os elementos extraliterários, problematizados, daí surgindo o imprevisível e o imponderável, pois a obra não mais se interessa em apoiar-se em um referente que estivesse fora dela. Por essa razão, a obra literária abriu-se para sua própria invenção, surgindo, assim, o arbitrário e o inconseqüiente (GOULART, 1995, p.33).

Se considerarmos a linguagem como não transparente, sujeita a imposições, ideologias e a equívocos do inconsciente, nenhuma escritura, por mais alegórica ou fantástica que seja sua forma de narrar, está desatrelada da realidade social e da conseqüente inserção da subjetividade que a realizou. Qualquer reflexo artístico tem de ser entendido como uma práxis humana realizada por um sujeito histórico em uma sociabilidade que tem espaços e tempos condicionantes.do sujeito social que a realiza.

Em muitos estudos a revolução formal é abordada sem a contraparte histórico-literária, o que, em alguns casos. resulta em perder de vista o sentido abrangente dessa mesma revolução. É Adorno quem diz que "onde a arte é experimentada apenas esteticamente ela deixa de ser experimentada mesmo esteticamente" (BASTOS. 2001. p.42).

Para os críticos, Murilo Rubião é a grande expressão da literatura fantástica moderna brasileira. Heliônia Ceres, a nosso ver, em Olho de besouro, segue os passos desse autor, fazendo de sua 
escritura um grito de dor dos desvalidos e buscando, através de imagens contraditórias que podem ser vistas sob ângulos diferentes, explicitar angústias e crueldades que se manifestam em uma sociedade baseada no individualismo exacerbado.

Em Murilo Rubião a crueldade da literatura é matéria de ficção. Representam-se ao mesmo tempo um mundo arcaico em vias de desaparecer e o meio ou o instrumento de sua destruição - a escrita, a literatura (BASTOS, 2001, p.49).

Em todos os contos do livro de Heliônia Ceres, verifica-se a crítica arguta às opressões a que o ser humano está sujeito, aliada a uma certa perplexidade e à constatação da impossibilidade de soluções cotidianas. O devaneio, a loucura, o fantástico se apresentam então como o caminho possível para o reflexo artístico.

São 12 contos que convidam a refletir sobre o sofrimento humano, sobre a razão do mundo e o olhar sobre o mundo que o reflexo artístico pode ter e, acima de tudo, cria-se pela realização metafórica que pressupõe uma metáfora anterior ${ }^{2}$, uma discussão cobre o papel da arte no mundo contemporâneo. É necessário compreender esse olhar capaz de perceber vários ângulos, como "Olho
de besouro".

O que é estar fora da realidade, do cotidiano? Construir contos que narrem fatos fantásticos ou propor soluções para a resolução de problemas ainda não permitidas pelas relações sociais postas em um a narrativa. A histórico? Esse é o questionamento unificador de toda questiona, alerta o leitor, surpreende e é surpreendida de nada, apenas das personagens.

No conto "Rosália das visões", que abre o livro Olho de besouro, a fragilidade feminina é discutida sob dois ângulos: o da mulher que não consegue fazer nada frente ao poder masculino e se deixa enlouquecer, e o da amiga que não descobre o caminho que possibilita alguma ajuda. É interessante ressaltar que esse conto, "Rosália das visões", dá título a um livro anterior da autora. Através dele, a autoria marca o caráter ambíguo de toda a narrativa: a

\footnotetext{
${ }^{2}$ Ver Mézáros, 1993.
} 
personagem tem visões que a afastam da realidade, ou possui a capacidade de olhar um fato por vários ângulos, a partir de enfoques diferentes? A temática dominante é árida, embora a escrita seja limpa, leve, como convém a quem não receia expor contradições. No conto de abertura do livro há um convite à união, um pedido de ajuda para o entendimento do mundo e das possibilidades que homens e mulheres possam adquirir para transformá-lo.

Levantou a cabeça com orgulho e segurou ainda mais forte naquela mão. Era já uma forma de poder. Embora ainda estivesse tateando, estava pronta (CERES, 1998, p.9).

A narrativa leva à reflexão de que não há possibilidade de individualidade e de produção individual que não seja essencialmente histórica e social. A explicação para a atividade da subjetividade no mundo não será dada por nenhuma condição que não possua explicação na própria sociabilidade, mesmo quando a subjetividade contemporânea busca soluções transcendentais que, no entanto, também serão explicadas pela sociabilidade. Há sempre um nexo entre subjetividade, sociedade e produção de idéias, entre elas, a produção literária.

Nesse primeiro conto, toma-se contato com vazios, silêncios, próprios de um mundo moderno que faz com que a solidão possa se dar tanto para aquele que está só como para os que estão rodeados de pessoas.

Procura criaturas que anoitecem e amanhecem sem ter a quem dizer alô! [...] Outros rezavam ... Era tão grande o silêncio que se ouvia correr o sangue dentro de cada um deles e o perpassar do próprio pensamento (p.7).

A abertura do livro traz uma narrativa de vozes que refletem apenas vazios. É um conto sobre a incomunicabilidade existente no cotidiano, o desencontro que a realidade do individualismo traz em seu cerne.

Aprendera com Rosália que eram eles os ruídos da solidão. Dos compartimentos vazios. Dos lugares desertos. Das palavras mortas. Dos pensamentos sem eco (p.7). 
A própria materialidade discursiva traz, no nível do intradiscurso ${ }^{3}$, as marcas da impossibilidade de comunicação. Cada uma das afirmativas é estanque, fechada em si mesma pela opção da pontuação que finaliza (o ponto final); não há comunicação entre lugares, palavras e pensamentos.

$\mathrm{Na}$ segunda narrativa ("Ofélia"), se há o anúncio da necessidade de comunicação direta com o mundo através de qualquer intermediário, esse é Olavo, o papagaio da família, que desperta a filha após a morte da mãe, utilizando a mesma fala desta ao se dirigir à filha:

\section{O/FÉ/LIA/VE/NHA/CÁ (p10).}

Ofélia obedece ao apelo do animal faminto e desperta para a vida sabendo que, como o papagaio vive cem anos, teria a certeza desse tempo para viver. É interessante observar a forma como foi dividida a fala do animal: a palavra Ofélia vira FÉ e LIA; se tem FÉ e LÊ então pode ver, enxergar, voltar ao mundo, quase que ressuscitar do surto psicológico em que se encontrava desde a morte da mãe:

E fora um impacto tão grande que deixara os rebocos que a fascinavam, para atendê-lo. Oferecer-lhe o café da manhã. Ocupar-se dele durante cem anos (p.12).

No conto "Os gatos", a relação de classe é discutida claramente através das relações entre patroa e empregada. Anita cria os filhos da patroa, ama-os, dá-lhes carinho, mas é dispensada quando não obedece às ordens de retirar os gatos da casa. Interessante é que a narradora se assusta com o afastamento de Anita, mas durante a narrativa tenta amenizar os lugares sociais diferentes ocupados por patrão e empregado, agregando a essa relação a afetividade das pessoas da casa pelas empregadas domésticas:

Anita fora alguém inesquecível para nós, mas apesar disso, outras vieram que a substituíram na direção da casa e no cuidado pessoal das crianças.

Posso até falar de Zefinha ou Mariana, pessoas tão dedicadas que passaram a ter conosco outra espécie de parentesco, desse que o amor cria (p.15).

Para o desenvolvimento dos conceitos de intradiscurso e interdiscurso, ver Courtine (1981). 
No conto "Querida Lucy", há um questionamento sobre a adequação de discursos logicamente construídos que fazem, inclusive, uso de conceitos científicos, como os usados pelos médicos para definirem as políticas de saúde pública até os que tentam explicar as contradições da realidade social. Na carta que escreve à prima, o narrador relata o seguinte fato:

Aluguei um carro de som e saímos pelos bairros pobres tentando salvar da peste o povo de Estrela, a dizer-lhe que não podiam conviver com moscas nem apanhar comida nos monturos, deviam lavar as mãos antes das refeições e evacuar nas latrinas. Logo percebemos que não havia refeições, latrinas e até mesmo água. Nós somos para eles como arautos de um mundo inexistente (p.68).

Nessa passagem observa-se que o narrador constata, estupefato, que esses discursos podem estar muito mais deslocados da realidade do que a representação, por exemplo, de uma peça no circo, que se propõe a fantasiar a realidade.

Aí aconteceu o que quero te contar. De dentro do meu espanto apareceu tia Clara. Tu crês que ela veio fantasiada de palhaço, dando cambalhotas no ar e fazendo números que nem podes crer? Será que é isso mesmo que ela quer que eu faça? Sei que agora não estamos fazendo jogo de palavras (p.69).

A última frase da citação - sei que agora não estamos fazendo jogo de palavras -vem demonstrar a clareza que o narrador, nesse caso particular, aquele que conduz o projeto autoral ${ }^{4}$, tem do significado da arte, da literatura enquanto um texto ficcional, e a impropriedade de discursos que ficcionam a realidade produzindo um deslocamento de mensagens que contribuem para o aprofundamento das disparidades sociais, e, o que é ainda muito mais grave, tendem a imobilizar a subjetividade na busca de soluções para seus problemas. A arte, ao contrário, cria possibilidades, alerta para as várias visões.

O narrador tem certeza do lugar em que a arte caminha, mas questiona se isso basta para os objetivos daquela população. Nesse

4 Para maior detalhamento sobre as várias formas utilizadas pela autoria para conduzir o projeto autoral, ver Magalhães, 2001. 
jogo entre real e fantasia, a função da arte é levar a esses questionamentos de forma bela; o belo não significando esconder o feio, mas dizê-lo artisticamente. Como faz o poeta ao se referir àqueles que nada possuem:

O sujeito atingido pela fome é um padecente do nada, um indivíduo pelas margens, pelas beiras, mais para inseto que coisa nenhuma, um sem, uma coisa sem nome, sem porto, à deriva, pastando as dores das entranhas roídas, um jogado, um sujeito com fome (CABRAL, 1998, p.67).

O pensamento mágico também é uma forma de resolução dos problemas sociais que não encontram resposta na realidade concreta; no entanto, diferentemente da arte, não contribui para a formação da subjetividade, ao contrário, anula-a, pois desloca para outros seres, que não homens e mulheres concretos, a resolução das dificuldades. A subjetividade é apagada e reduzida a simples executora obediente de regras impostas por esse tipo de expressão humana, que desloca o eixo das resoluções da realidade histórico-social.

Ratificando o afirmado acima, tem-se que a arte, ao contrário do pensamento mágico, parte de indivíduos concretos e retorna a eles através da recepção, sendo, em todas as suas fases, um fenômeno essencialmente social.

No conto "A procissão dos encapuzados", título de outro livro da autora, o narrador se posiciona com total incredulidade sobre as crendices populares; no entanto, acaba por sucumbir aos apelos mágico-religiosos da localidade onde viveu a infância.

Como e por que devo preocupar-me em saber o que sou ou deixo de ser, quando tenho mais o que fazer para viver o dia que passa?[...] Eles insistem em chamar-me, o rumor é cada vez tão alto que não posso mais me conter, quem me chama, quem me chama? Esperem, esperem, por favor, eu estou aqui...que querem vocês de mim???(p.35-7).

Nada de mágico acontece que não possa ser explicado, por exemplo, pela psicanálise ou pelas relações sociais que deram origem às procissões. Não importa aqui a conclusão do narrador, mas as marcas que foram oferecidas pela autoria para explicar os 
questionamentos do homem comum sobre a condição humana - de repente, me espia e passa a exigir que eu me justifique de minha vida, de meus atos (p.36).

$\mathrm{Na}$ verdade, o uso de traços alegóricos, a construção de personagens que não fazem parte do cotidiano, a busca de forças sobrenaturais que fazem apelo à magia não afastam, necessariamente, a literatura da realidade. Heliônia Ceres discute essa questão ao demonstrar que o cotidiano do fazer a comida, servir a mesa, dirigir um táxi, pode conviver com gatos, demônios, besouros, bruxas que perscrutam cada ato e são capazes de desestabilizar o cotidiano e a narrativa, levando-os para a verdadeira fantasia.

De repente, emudeceu. Ofegante, sem sapatos, sentia-me perdida. Olhei de relance para trás, não havia mais ninguém. A luz da vela, inclusive, havia se apagado. Entrei gritando na casa de Zilah (p.31).

O resultado do fazer artístico representa uma visão de mundo, sem que haja uma relação mecânica entre o que o artista pensa sobre o mundo e o que expressa em sua obra. $O$ ato artístico é sempre consciente, o sujeito que o realiza tem consciência do que quer realizar, embora não tenha controle total sobre a capacidade de dar forma ao seu objetivo, nem da totalidade de interpretações que poderão advir de sua intencionalidade ${ }^{5}$ expressa na obra. Essa intencionalidade é reafirmada por Bakhtin(1992, p. 300), através do conceito de intuito discursivo, que pressupõe o querer dizer do autor de um texto:

Em qualquer enunciado, desde a réplica cotidiana monoleximática até as grandes obras complexas científicas ou literárias, captamos, compreendemos. sentimos o intuito discursivo ou querer dizer do locutor que determina o todo do enunciado: sua amplitude. suas fronteiras. [...] $O$ intuito, o elemento subjetivo do enunciado, entra em combinação com o objeto do sentido - objetivo - para formar uma unidade indissolúvel, que ele limita, vincula à situação concreta (única) da comunicação verbal, marcada pelas circunstâncias individuais, pelos parceiros individualizados e suals intervenções anteriores: seus enunciados.

5 Intencionalidade, que significa o pôr do sujeito no mundo. o ag̣i com objetivo, por isso agir a partir de uma reflexão prévia sobre o ato. 
Os seres mais corriqueiros da vida cotidiana: empregadas, taxistas, mulheres abandonadas, mães zelosas, estudantes aplicadas, realizam suas tarefas, mas, sempre de repente, sem nenhum aviso prévio, saltam à procura do sentido da vida, da justificativa da solidão humana, da busca da felicidade que não pode ser de um, pois só acontece se compartilhada.

Eu me pergunto mil vezes por que deveria estar hoje nessa cidade. Porque começo a me questionar e a ver esse olho que, de repente, me espia e passa a exigir que eu me justifique de minha vida de meus atos (p.36).

$\mathrm{Na}$ verdade, há um duplo aspecto a ser considerado: todo processo de objetivação do fazer estético é orientado pelo momento subjetivo, que pressupõe leitura do mundo, intencionalidade, conhecimento técnico e, se possível, genialidade; e, ao mesmo tempo, todo resultado obtido possui pretensão de validez objetiva. Nas palavras de Lukács (1968, p.267):

Como vimos, a particularidade como categoria específica do campo estético é, negativamente, a renúncia a reproduzir a totalidade extensiva da realidade; e, positivamente, a representação de uma "parte" da realidade, representação que - reproduzindo a sua totalidade intensiva e a direção do seu movimento clarifica a realidade através de um determinado e essencial ponto de vista.

No texto, os narradores se deparam com os "absurdos" da vida e se questionam sobre o lugar que ocupam na existência: são atos desconexos, rompimentos de regularidade, ou, ao contrário, incongruências costumeiras que passam por gerações e tomam matizes diferentes dependendo do momento histórico.

A autoria vacila e se volta para o conhecido, mais fácil de ser controlado. A angustiante encenação de papéis previamente definidos, que não correspondem ao pensamento, que podem ser até antecipados pela imagem passada, porque sempre ocorrerão.

— "Muito bem, muito bem, você está saudável!" E eu rirei e agradecerei. Eu estarei penteada, de roupa nova, sobrancelhas feitas e olhos brilhantes e rirei novamente. Então, ele tomará meu pulso cautelosamente, medirá 
minha pressão e sossegará. Lolita abrirá sua bagagem, trará perfumes e novos vestidos, dar-me á notícias de todos os que ficaram. Esses também remeterão presentes que abrirei pressurosa e os encostarei ao coração (p.52$3)$.

Esse conto "Pergunte a outra pessoa" faz um diálogo com o conto "Amor", de Clarice Lispector, pois aponta para uma necessidade intrínseca do ser social de uma desestabilização, de uma saída do real, exatamente para poder voltar a ele de forma diferente, embora realizando as mesmas atividades.

Ela continuou sem força em seus braços. Hoje de tarde alguma coisa tranqüila se rebentara, e na casa toda havia um tom humorístico, triste. É hora de dormir, disse ele, é tarde. Num gesto que não era o seu, mas que pareceu natural, segurou a mão da mulher, levando-a consigo sem olhar para trás, afastando-a do perigo de viver (LISPECTOR, 1995, p.41).

Embora fosse cobrada a rotina da hora de dormir, o marido percebe algo de novo e, "num gesto que não era o seu", isto é, que não fazia parte da rotina, leva a mulher para o quarto, para o rotineiro. Mesmo sutilmente as coisas mudaram, embora pareçam as mesmas. Essa contradição de necessitar de uma regularidade do cotidiano, de uma certa rotina e, ao mesmo tempo, também precisar sair desse lugar, está no cerne da lógica de criação do novo, do desenvolvimento social, mas trazendo para cada ser, individualmente, grandes angústias.

As personagens deste livro estão sempre lutando para que o cotidiano siga seu rumo sem nenhum tropeço, como galinhas ciscando e botando ovos; no entanto, sempre há algo para desestabilizar o cotidiano: vozes, campainhas, gatos, fantasmas que demonstram não ser possível viver sem perigo.

Considerando que na gênese do ser social ${ }^{6}$ está sua capacidade de criação do novo, a instabilidade, o absurdo, o inevitável são parte constitutiva do processo histórico, e, inclusive, da possibilidade de transformação social pelo gênero humano A literatura fantástica transforma essa capacidade humana incontrolável em perplexidade.

\footnotetext{
${ }^{6}$ Ver Lukács (1966-67).
} 
traduzida em acontecimentos inusitados, seres absurdos, bruxas, fantasmas. Por isso as personagens lutam tentando não pensar, mas isso significa morrer.

Sintetizando, pode-se afirmar que toda a objetivação artística possui um ponto de vista autoral. $\mathrm{Na}$ verdade, estamos nos referindo ao posicionamento do autor sobre a realidade refletida na obra, à marca de sua intencionalidade ao escolher aquele conjunto de códigos e não outro para refletir na sua obra.

Com isso está-se afirmando que existe sempre um projeto consciente de autoria, trazendo implícita uma visão sobre a realidade refletida, que pode ser expresso de formas as mais diversificadas. A crítica de arte, sob essa perspectiva, precisa encontrar o caminho escolhido pelo autor para expressar uma determinada realidade histórica, captando, através do uso de categorias intelectivas, a relação dialética explicitada pelo autor na obra, que necessariamente apresentará um ponto de vista de um sujeito particular e, ao mesmo tempo, expressará uma possibilidade da humanidade em relação à resolução das questões selecionadas pelo autor.

O projeto autoral de Heliônia Ceres nesse livro unifica dialeticamente os contrários, fazendo com que o mundo fique muito mais rico. Não dá receitas, não julga, apenas dialoga com as diversas vozes que compõem o ser social. Por isso, algumas personagens preferem voltar para o mesmo lugar, mesmo sabendo que pode haver outras formas de viver - Apanhamos então o carro de volta para casa. Não havia mesmo porque não voltar(p.55). Outras vivem porque não obedecem e porque usam o olho de besouro para encontrar a saída Levantei da cama doidamente, valises e sacolas espalhadas pelo chão, apanhei o passaporte e fugi(p.61).

A vida em sua plenitude está contida na obra de arte, como afirma Bakhtin (1993): a forma estética tem o poder de transferir essa plenitude para um outro plano, que, no entanto, nunca pode significar, do ponto de vista da crítica, isolamento de partes dessa expressão artística, mas, ao contrário, necessita captar esse momento único em sua plenitude, seguindo o projeto do artista:

Não pode ser destacado da obra de arte um elemento real qualquer como sendo conteúdo puro, como, aliás. realiter não há uma forma pura: o conteúdo e a forma se interpenetram. são inseparáveis, porém, também são 
indissolúveis para a análise estética, ou seja, são grandezas de ordens diferentes: para que a forma tenha significado puramente estético, o conteúdo que a envolve deve ter um sentido ético e cognitivo possível, a forma precisa do peso extra-estético do conteúdo, sem o qual ela não pode se realizar enquanto forma (BAKHTIN, 1993, p.37).

A autoria, pela mão dos narradores, alinhava cada história e, como dizem Bakhtin e Lukács, pinça da realidade os fatos, mas sempre com olho de besouro, de mãos dadas; unindo vida e arte, convida ao fascínio ficcional através de, por exemplo:

1) uma serviçal competente, descartada porque invade a cena através de seus gatos e imobiliza os habitantes da casa. Para que tudo volte ao normal, não pode haver mudanças. E porque estávamos cansados, continuamos calados. Levantamo-nos em seguida e com que ansiedade passamos a acender, uma por uma, as lampadas da casa (p.19). Não havia mais perigo, Julinho não viajaria, a rotina poderia ser retomada.

2) uma fórmula mágica que só as mulheres podem saber, para solucionar problemas, porque só elas unem coração e razão; no entanto, nenhuma delas pode sozinha dominar todo o conhecimento, tem de dividi-lo, sob o risco de querer dominar tudo e todos. É necessário olhar em todas as direções, para poder compreender que as pessoas não podem admitir suas diferenças sob o risco de perderem a própria identidade e pagarem com a vida, aquilo que o outro quer saber(p.24). Por isso a narradora oculta sua verdadeira essência, a capacidade de ter visões, usando o silêncio como estratégia definitiva de preservação de sua individualidade diferenciada.

3) o medo do desconhecido, daquilo que fica no subterrâneo, guardado nos quintais, no toque de uma campainha e que pode vir à tona repentinamente, sem aviso e dominar todo o ser. Para as duas. houve um sinal. Alguém as chamara e teriam de esperar. Não fora ninguém. Mas a campainha anunciara (CERES, 1998, p.44).

Esse o fio condutor que une todos os contos: a realidade objetiva que expressa a secura da vida e as buscas internas do eu e do significado da vida. Por que começo a me questionar e a ver esse enorme olho que, de repente me espia e passa a exigir que eu me justifique de minha vida de meus atos(p.36). Para as resoluções da 
contradição entre a subjetividade e o cotidiano, há a fuga para um lugar construído aparentemente para negar as contradições, mas que, na verdade, as explicita e torna possível a solução, só que apenas de forma artística. Preciso continuar a escrever tudo o que ocorre nesse momento porque sou um homem que tem os pés no chão e não posso deixar envolver-me por essa atmosfera de medo e alucinação, sei lá?(p.36). A tentativa de controle através da racionalização da escrita escapa pela própria escrita - sei lá! -. Não consegue definir o que é, logo não pode controlar.

Como as personagens Vitória e Mariana, tão zelosas com a casa e as plantas, porém imobilizadas ante a perspectiva de algo desconhecido que fez tocar a campainha. No entanto, Mariana sempre cantava quando sofria (p.38). A autoria está sempre alertando, através de peripécias, tão bem estudadas por Aristóteles para a explicação das mudanças de ações nas tragédias, fazendo com que o descompasso entre cantar e sofrer apareçam como algo normal e o toque de uma campainha provoque uma mudança radical no dia-a-dia das duas irmãs.

Heliônia Ceres demonstra, como o personagem Riobaldo, de Grande sertão: veredas, de Guimarães Rosa, que viver é muito perigoso, não somente pelas inseguranças da rua, mas pelos tormentos da casa, onde se escondem os sonhos, as vozes internas e as visões.

Têm-se sempre atos corriqueiros, bem enquadrados, personagens objetivos sem grandes questionamentos, que esperam da vida apenas o que se apresenta como possível:

Era essa hora e eu deveria apresentar-me logo mais no Departamento de Viaturas Públicas para aferir o taxímetro de meu carro com o novo preço, a filla era grande para enfrentar, meus camaradas esperando lá desde as dez ou onze horas do dia anterior, eu sem querer passar toda a noite em claro, cochilar e ou roncar à toa; além do mais, Dulce no hospital para a terceira cesariana, eu e a mulher para conhecer o neto, isso de família (p.45).

De súbito, os personagens não conseguem controlar e explicar alguns acontecimentos. Ficam presos ao inusitado, acusam o mundo, o outro, pela quebra do rotineiro; no entanto, as marcas comprovam que o rumo foi mudado, nada pode ser como antes. Eu não podia aceitar 
que tudo aquilo fora uma grande mentira porque lá estavam gravadas com fúria, no meu pescoço, as marcas fundas das presas daquele cão(p.49). Ninguém está a salvo, sempre existe algo escondido que pode ser deflagrado a qualquer momento - mas eu sabia que existe sempre uma razão escondida por trás das coisas (p.51).

Essa busca da razão das coisas e do limite da subjetividade como força impulsionadora do mundo está presente no mundo. No entanto, a autoria vacila entre uma intervenção objetiva, como a participação política do primo de Lucy, e o apelo à fantasia artística. O título do último conto, "As bruxas? Elas existem sim!", sintetiza a pergunta que perpassa todos os contos: o que é possível acionar para a resolução dos conflitos que atormentam o ser humano no seu cotidiano? A resposta não é definitiva; transita entre o apelo ao sonho, a seres transcendentais, às forças da natureza, como o vento; ao chamado de um animal, 'como o papagaio que tira Ofélia da letargia.

O cotidiano e a magia convivem nesse livro através de um relacionamento seguro do reflexo estético que, embora se surpreenda com e através delas, possui o controle de todas as personagens. Por isso a autoria inicia convidando ao congraçamento - mãos dadas - e termina constatando que "a velha bruxa sorria".

A arte cumpre o seu papel, e a autoria, pela voz de uma de suas personagens, afirma - suponho que a muitos parecerá ilusão, quem sabe fantasia, mas não é (p.72).

E conclui a crítica literária: é vida, refletida pela arte. 


\section{Referências bibliográficas}

ADORNO, Theodor W. Teoria estética. Tradução Artur Morão. Lisboa: Edições 70, [.s.d.].

BAKHTIN, Mikhail. Questões de literatura e de estética. Tradução Aurora Fornoni Bernadini et al. 3. ed. São Paulo: Hucitec, 1993.

BAKHTIN, Mikhail. Estética da criação verbal. Tradução Maria Ermantina Galvão Gomes. São Paulo: Martins Fontes, 1992.

BAKHTIN, Mikhail. Marxismo e filosofia da linguagem. Tradução Michel Lahud e Yara Frateschi Vieira. São Paulo: Hucitec, 1990.

BARTHES, Roland et al. Literatura e sociedade: problemas de metodologia em sociologia da literatura. São Paulo: Mandacaru, 1989.

BASTOS, Hermenegildo José. Literatura e colonialismo: rotas de navegação e comércio no fantástico de Murilo Rubião. Brasília: Edunb,2001

BENJAMIN, Walter. Magia e técnica, arte e política. Tradução Paulo Rouanet. 4. ed. São Paulo: Brasiliense, 1985.

CABRAL, Otávio. Comeram Dom Pero Fernão de Sardinha: a possibilidade da situação trágica numa estrutura épico-brechtiana. Maceió, 1998. Dissertação de Mestrado, Universidade Federal de Alagoas.

CANDIDO, Antonio. O discurso e a cidade.São Paulo: Duas Cidade, 1993.

CAPOMASSI, Alicia; VÁZQUEZ María Celia. El autor o la ressurrección de una inestabilidad. In: Literatura e diferença. São Paulo: IV Congresso da Abralic. Anais, 1994.

CERES, Heliônia. Olho de besouro. Curitiba: HDLivros, 1998.

COURTINE. Jean-Jacques. Anlayse du discours politique.Paris: Larousse, 1981.

GOLDMANN, Lucien. A sociologia do romance. Tradução Álvaro Cabral. 3. ed. Rio de Janeiro: Paz e Terra, 1976.

GOULART, Audemaro Taranto. O conto fantástico de Murilo Rubião.Belo Horizonte: Ed. Lê, 1995. 
LISPECTOR, Clarice. Laços de família. 27. ed. Rio de Janeiro: Francisco Alves, 1994.

LUKÁCS, Georg. Introdução a uma estética marxista. Tradução Carlos Nelson Coutinho e Leandro Konder. Rio de Janeiro: Civilização Brasileira, 1978.

LUKÁCS, Georg. Marxismo e teoria da literatura. Rio de Janeiro: Civilização Brasileira, 1968. A fisionomia intelectual dos personagens artísticos.

LUKÁCS, Georg. Estética: la peculiaridad de lo estetico. 4 v. Barcelona/México: Grijalbo, 1966-67.

MAGALHÃES, Belmira Vidas secas: os desejos de sinha Vitória. Curitiba: HDLivros,2001.

MAGALHÃES, Belmira. Plus ultra: o segredo da arte. Revista Estudos. Maceió: Ufal, 1995.

PECHÊUX, Michel. L'ínquiétude du discours. Paris: Éditions de Cendres, 1990.

ROSA, Guimarães. Grande sertão: veredas. 27. ed. Rio de Janeiro: Nova Fronteira, 1986.

WILliAMS, Raymond. O campo e a cidade: São Paulo: Companhia das Letras, 1989. 